\title{
The value premium, aggregate risk innovations, and average stock returns
}

Knut F. Lindaas

Prodosh Simlai

University of North Dakota, prodosh.simlai@und.edu

\section{How does access to this work benefit you? Let us know!}

Follow this and additional works at: https://commons.und.edu/ef-fac

Part of the Economics Commons

\section{Recommended Citation}

Knut F. Lindaas and Prodosh Simlai. "The value premium, aggregate risk innovations, and average stock returns" (2014). Economics \& Finance Faculty Publications. 9.

https://commons.und.edu/ef-fac/9

This Article is brought to you for free and open access by the Department of Economics \& Finance at UND Scholarly Commons. It has been accepted for inclusion in Economics \& Finance Faculty Publications by an authorized administrator of UND Scholarly Commons. For more information, please contact und.commons@library.und.edu. 


\title{
The value premium, aggregate risk innovations, and average stock returns
}

\author{
Knut F. Lindaas \\ Boston University \\ Prodosh Simlai ${ }^{1}$ \\ University of North Dakota
}

\begin{abstract}
We test whether innovations in aggregate risk, interpolated from a vector autoregressive system that contains the Chen, Roll and Ross (1986) five factors as in Petkova (2006), are common factors in crosssectional stock returns. We provide direct evidence that innovation in industrial production growth, a classical business-cycle variable that summarizes the state of the economy, is associated with the crosssectional return predictability of individual stocks. We conclude that the role of innovation in aggregate risk is not random, and furthermore that it provides guidance concerning an important source of nonfinancial market-based risk in asset returns.
\end{abstract}

JEL classification: G12; G14

Keywords: firm size; book-to-market; risk innovations; industrial production growth; investment opportunity

${ }^{1}$ Corresponding author. Address: 293 Centennial Drive, Grand Forks, ND-58202-8369; Ph: 1-701-777-3360; Fax: 1-701-777-3365; Email: psimlai@business.und.edu. 


\section{Introduction}

In this paper we evaluate the pervasive role of aggregate risk factors in changes in a given investment opportunity set. We investigate whether innovations in state variables are important for explaining asset pricing anomalies related to market capitalization and book-to-market equity. Our goal is to explore a number of aggregate state variables that can potentially influence cross-sectional return variability in our testing assets. We demonstrate that at the individual firm-level, aggregate risk innovation is a more important determinant of average cross-sectional returns than has previously been shown.

Specifically, we investigate whether the size effect and the value effect, which are often associated with market equity $(M E)$ and book-to-market ratio $(B E / M E)$ respectively, are related to the surprise component of aggregate risk factors. The size and value effects show that certain portfolios of stocks tend to have higher returns than others. Since the anomalous nature of stock returns goes against the predictions of various models asserting that firm-level characteristics should not influence the crosssection of stock returns, the size and value effects have faced intense scrutiny in academic research ${ }^{2}$.

In order to explain asset returns with business-cycle fundamentals, we follow the widely cited unconditional approach of Chen, Roll, and Ross (CRR 1986), and choose their set of five relevant aggregate factors. Similar to Petkova (2006), we use a multivariate vector autoregressive (VAR) model to extract innovations from the raw aggregate factors. We focus on variables such as the growth rate of industrial production (GIP), which summarizes the state of the economy, and relate the innovations to average returns for a set of well-known Fama-French (1993) portfolios two-way sorted on market equity and book-to-market ratio. One simple result emerges: Innovation in GIP is revealed to be a significant priced risk factor and is related to cross-sectional return predictability. We conclude that the relationship between expected return and the component of aggregate risk related to innovation in GIP is positive and not flat. We also perform an individual firm-level analysis to evaluate the role of GIP innovation risk for individual stocks. The results demonstrate that the spread between value and growth portfolios becomes much weaker once we control for GIP innovation. Furthermore, we perform a Fama-MacBeth (1973)

\footnotetext{
2 The relation between average stock returns and firm characteristics such as $M E$ and $B E / M E$ has already been investigated in numerous studies. Recent work by Fama and French (2012) and Asness et al. (2013) suggest that there are value premiums in average stocks returns that, except for Japan, decrease with size. In a related paper, Novy-Marx (2013) uses gross profitability as a measure of profitability and shows that the value premium is not driven by unprofitable stocks. Hwang and Rubesam (2013) provide a behavioral explanation of the value-growth anomaly based on time-varying return reversals. Choi (2013) argues that the dynamic interaction between asset risk and leverage drives the value premium.
} 
cross-sectional regression for individual stocks, using firm-level characteristics and the loadings on the innovations. No previous study provides such a breakdown of the cross-sectional variability of individual stocks in the presence of innovation in GIP.

Our paper is closely related to the recent work of Cooper and Priestley (2009), who suggest that the output gap, a prime business cycle indicator, predicts aggregate stock and bond market returns. However, in contrast to our GIP innovation, Cooper and Priestley (2009) measure the output gap by the deviations of the log of IP from trend that incorporate both a linear and a quadratic component. Furthermore, unlike Cooper and Priestley (2009), who analyze stock returns on the CRSP value-weighted index and the S\&P 500 index, we focus on portfolios and individual stocks sorted by well-known firm-level characteristics that have implications for equity allocation. Finally, our primary focus is the cross-sectional role of GIP innovation in our testing assets. Our approach is therefore complementary, and the contributions of this paper are limited by the robustness of the current results.

The rest of the paper is organized as follows. Section 2 reviews the prior literature and explains what motivates our idea. Section 3 briefly describes the methodology and models of performance measurement used throughout the paper. Section 4 presents our main empirical results. In section 5 we conclude with some brief comments.

\section{Motivation and prior literature}

The key insight of Merton's (1973) intertemporal capital asset pricing model (ICAPM) is that the equilibrium pricing kernel depends on the state variables of the return generating process. Thus, in equilibrium we have the following relationship between expected return and risk:

$$
E_{t}\left(R_{i, t+1}\right)=\delta \cdot \operatorname{Cov}_{t}\left(R_{i, t+1}, R_{M, t+1}\right)+\Delta^{\prime} \cdot \operatorname{Cov}_{t}\left(R_{i, t+1}, Q_{t+1}\right)
$$

where $R_{i, t+1}$ is the return of asset $i$ in excess of the risk-free rate at time $t+1, R_{M, t+1}$ is the excess market return at time $t+1, Q_{t+1}$ is a vector of $k$ state variables that shift the investment opportunity set, $\delta$ is a scalar, $\Delta$ is a $k \times 1$ vector that prices all assets, and subscript $t$ denotes the conditionality of information available at time $t$. Recent empirical literature suggests that macroeconomic risk might proxy for $Q_{t+1}$, which describes the variability in the investment opportunity set. There is a large body of work which implements empirically testable versions of (1), and utilizes levels of macroeconomic state variables that price the cross-section of stock returns (see e.g., Lettau and Ludvigson (2001); Brennan et 
al. (2004); Campbell and Vuolteenaho (2004); Petkova (2006); Shanken and Weinstein (2006); Liu and Zhang (2008); Krishnan et al. (2009); Aretz et al. (2010); and Fong (2012)) ${ }^{3}$.

Despite the existing work, there have been few attempts to see whether the effect of aggregate economic factors, which forecast changes in investment opportunity sets, are illusory or real and supportable by data. In the literature, we see limited utilization of the innovations of common risk factors that summarize the state of the economy as a priced risk factor. Unlike the previous works, in this study we focus on the innovations in the set of CRR aggregate risk factors as driving the pricing kernel (1). Representative recent works that include a similar set up and variables are Guidolin, McMillan, and Wohar (2013), Liu and Zhang (2008), Petkova (2006), and Shanken and Weinstein (2006). Compared to Shanken and Weinstein (2006), and Liu and Zhang (2008), we evaluate the incremental role of the innovation in GIP in the presence of four other CRR risk factors and excess market returns. Petkova (2006) doesn't demonstrate whether the superiority of the model comes from its ability to explain cross-sectional returns of individual stocks. Furthermore, unlike Guidolin, McMillan, and Wohar (2013), we provide results to justify the non-random role of state variables in double-sorted (two-dimensional) portfolios. As mentioned by Campbell (1996, p.300), implementation of (1) should rely on the innovations in state variables that help to forecast future investment opportunities. Motivated by that argument, in the empirical tests of the paper we focus on the innovations of all five CRR risk factors.

\section{Empirical methodology}

Following Cochran (2005, ch.12), we consider a linear multifactor factor model with observable factors $f=\left(f_{1}, \ldots \ldots, f_{K}\right)^{\prime}$ and a vector of exposures to risk factors $\beta=\left(\beta_{1}, \ldots \ldots, \beta_{K}\right)^{\prime}$. The empirical modeling applied in this paper is premised on the evaluation of a factor pricing model with multiple factors

$$
E\left(R_{i}\right)=\beta^{\prime} E(f)
$$

by running time-series regressions

$$
R_{i, t}=\beta_{0, i}+\beta_{i}^{\prime} f_{t}+\varepsilon_{i, t}, t=1, \ldots, T
$$

\footnotetext{
${ }^{3}$ For example, Aretz et al. (2010) examine a broad set of macroeconomic fundamentals and find that changes in GIP expectations and the term structure Granger-cause several macroeconomic fundamentals. In their investigation into the premiums earned by small-cap, value and momentum strategies, Arshanapalli, Fabozzi, and Nelson (2006) find evidence in support of a risk-based explanation for the small-cap premium. However, the same investigation did not find conclusive evidence in favor of a risk-based explanation for the value premium, as the value strategy was found to perform well during recessions and down stock markets. In a related paper, Maio and Santa-Clara (2013) use a three-factor conditional ICAPM in an attempt to explain the value premium and momentum anomalies. Furthermore, Engle, Ghysels, and Sohn (2013) suggest that economic fundamentals such as GIP play a significant role in explaining short-term and long-term component of stock market volatility.
} 
$\forall i=1, \ldots, N$. In (2), $R_{i, t}$ is the excess returns of asset $i$ at time $t$, and $f_{t}=\left(f_{1 t}, \ldots \ldots, f_{K t}\right)^{\prime}$. More precisely, in our time-series regression (2), the set of risk factors are represented by the estimated residual vector $u_{t}$ from the following parsimonious first-order VAR specification, as adopted in Petkova (2006):

$$
Q_{t}=\theta Q_{t-1}+u_{t}
$$

where the vector $Q_{t}$ consists of the demeaned values of the excess market return and five CRR factors defined in subsection 4.1. We can rewrite equation (2) as:

$$
R_{i, t}=\beta_{0, i}+\beta_{M, i} R_{M, t}+\beta_{\widehat{u}^{U I},{ }_{i}} \hat{u}_{t}^{U I}+\beta_{\widehat{u}^{D E I}, i} \hat{u}_{t}^{D E I}+\beta_{\widehat{u}^{U T S}, i} \hat{u}_{t}^{U T S}+\beta_{\widehat{u}^{U P R}, i} \hat{u}_{t}^{U P R}+\beta_{\widehat{u}^{G I P}, i} \hat{u}_{t}^{G I P}+\varepsilon_{i, t}(4)
$$

where $\hat{u}_{t}^{j}$,s are obtained from (3). Finally, we use the estimated time-series betas from (4) in the following cross-sectional regression across expected returns of all assets:

$R_{i, t}=\gamma_{0, t}+\gamma_{M, t} \hat{\beta}_{M, i}+\gamma_{\widehat{u}^{U I}, t} \hat{\beta}_{\widehat{u}^{U I}, i}+\gamma_{\widehat{u}^{D E I}, t} \hat{\beta}_{\widehat{u}^{D E I}, i}+\gamma_{\widehat{u}^{U T S}, t} \hat{\beta}_{\widehat{u}^{U T S}, i}+\gamma_{\widehat{u}^{U P R}, t} \hat{\beta}_{\widehat{u}^{U P R}, i}+\gamma_{\widehat{u}^{G I P}, t} \hat{\beta}_{\widehat{u}^{G I P}, i}+$ $u_{i, t}(5)$

In (5), $\hat{\beta}$ 's are the exposures to the corresponding factor, and $\gamma$ 's capture the reward for bearing the associated factor risk. Our final estimate and statistical significance of $\gamma_{j}$ in the $2^{\text {nd }}$ pass of the crosssectional model (5) are based on

$$
\hat{\gamma}_{j}=\frac{1}{T} \sum_{t=1}^{T} \hat{\gamma}_{j, t}, \quad \forall j .
$$

and the standard errors using the traditional Fama-MacBeth (1973) method. In order to avoid measurement error problems, in addition to traditional Fama-MacBeth (1973) version, we also report tstatistics based on Shanken's (1992) errors-in-variables-adjusted standard errors for our cross-sectional regression inference. The modified standard errors are given by following

$$
\sqrt{\left[s^{2}\left(\hat{\gamma}_{j}\right)-s_{j}^{2}\right](1+c)+s_{j}^{2}}
$$

where $s^{2}\left(\hat{\gamma}_{j}\right)=\frac{1}{T(T-1)} \sum_{t=1}^{T}\left(\hat{\gamma}_{j, t}-\hat{\gamma}_{j}\right)^{2}, c=\hat{\Gamma}^{\prime} \Omega_{f}^{-1} \hat{\Gamma}, s_{j}^{2}$ is the variance of the mean for factor $j$ (zero when $j=0$ ) in the second pass cross-sectional regression, $\hat{\Gamma}$ is the sample mean vector of estimated coefficients $\gamma_{j, t}(\forall j)$ in equation (5), and $\Omega_{\mathrm{f}}$ is the sample covariance matrix of the factor. In practice, we implement three different versions of equations (4) and (5). They include a simple model with only $\hat{u}_{t}^{G I P}$ as an explanatory variable, a multifactor model with innovations from all CRR factors, and a full specification (4). In the next section we provide the main empirical evidence of the paper. 


\section{Empirical evidence}

\subsection{Data}

We analyze two sets of data in this paper. For the first set, we obtain 25 size- and book-to-market-sorted portfolio returns, value-weighted market returns, and Fama-French factors from Kenneth French. Our sample commences in January 1962 and extends through December 2011. The second set includes all U.S firms traded on the NYSE, AMEX, and NASDAQ during the period from July 1963 to June 2011. Following the literature, we include firms with least five years of valid CRSP returns and exclude financials (SIC code 6000-6799) and utilities (SIC code 4900-4942). This sample of stocks from the NYSE-AMEX-NASDAQ universe is obtained from the CRSP-Compustat combined database. Following Fama and French (1993), we consider firms with positive $B E$ on Compustat and construct $B E / M E$ ratios. The $B E$ used in June of year $t$ is the book equity for the end of the last fiscal year $t-1$, and the $M E$ is price times shares outstanding at the end of December of $t-1$. The sample includes all ordinary common equity for which we have $M E$ for December of $t-1$ and June of $t$, and $B E$ for $t-1$. We choose to use the estimated GIP innovation beta and $B E / M E$ ratio of each stock to construct various sets of portfolios. The first set of portfolio is solely based on the estimated GIP innovation beta of individual stocks. The second set of portfolio is two-way sorted by the estimated GIP innovation beta and by $B E / M E$ of each stocks. We provide further details about these one and two-dimensional portfolios in subsection 4.4.

For aggregate risk characterizations, following Liu and Zhang (2008) we identify the aggregate factors as: $G I P_{t}=\ln \left(I P_{t}\right)-\ln \left(I P_{t-1}\right)$, where $I P_{t}$ is the index of industry production in month $t$ from the FRED database at Federal Reserve Bank of St. Louis; $U I_{t}=I_{t}-E\left[I_{t} \mid t-1\right]$ where $I_{t}=\ln \left(C P I S A_{t}\right)-$ $\ln \left(C P I S A_{t-1}\right)$, and CPISA $_{t}$ is the seasonal adjusted Consumer Price Index from the Labor Bureau of Statistics; $D E I t=E\left[I_{t+1} \mid t\right]-E\left[I_{t} \mid t-1\right]$, where $E\left[I_{t} \mid t-1\right]=R_{f, t}-E\left[R h o_{t} \mid t-1\right], R h o_{t}=$ $R_{f, t}-I_{t}, E\left[R h o_{t} \mid t-1\right]=\left(R_{f, t-1}-I_{t-1}\right)-\left(\hat{v}_{t}+\hat{\varphi} \hat{v}_{t-1}\right)$, and $R_{f, t}$ is the one-month T-bill rate; UTS is defined as a 20-year - 1-year treasury yield from the FRED database at the Federal Reserve Bank of St. Louis; and UPR is defined as the BAA-AAA yield from the FRED database at Federal Reserve Bank of St. Louis. In the next two subsections 4.2 and 4.3, we first consider the performance of portfolios. This is followed by our analysis of the individual stock level data in subsections 4.4 and 4.5 .

\subsection{Descriptive statistics and alpha measures}


We start with the basic descriptive statistics for the monthly excess returns of all the 25 size- and book-tomarket-sorted portfolios between January 1962 and December $2011^{4}$. As we expect, the summary of the average excess returns of all double-sorted portfolios, reported in Table 1, demonstrates that there is a significant value premium. The portfolios with higher $B E / M E$ ratios consistently generate higher average excess returns $^{5}$, and the average monthly portfolio excess returns always increase in the higher BE/ME quintiles. The average excess return on high- $B E / M E$ stocks is $0.88 \%$ per month and the average excess return on low- $B E / M E$ stocks is $0.37 \%$ per month. The value premium in our sample is higher for smallsize stocks and lower for big-size stocks ( $0.86 \%$ per month compared to $0.17 \%$ per month), which coincides with existing findings in the literature (see e.g., Fama and French (2012), Asness, Moskowitz, and Pedersen (2013)). The median-size and median- $B E$ / $M E$ portfolios generate average excess returns of $0.72 \%$ and $0.68 \%$ per month respectively ${ }^{6}$.

Table 1 also displays average alpha estimates from four different models. The first estimate is the intercept of a traditional market model, which we refer to as $1 \mathrm{~F}$ model alpha. The next two estimates are based on the intercept from two characteristic-based multifactor models, which use innovations of FamaFrench (1993) and momentum (Carhart (1997)) factors. We call these intercepts 3F model alpha and 4F model alpha respectively. The final set of estimates reports the intercepts from our time-series model (4), which includes excess market return and innovations of five CRR factors.

The first set of alpha estimates - the intercept from the market model - suggests that the value premium persists even after controlling for market risk. In terms of the abnormal returns, the $1 \mathrm{~F}$ model alpha estimates are smaller than the average excess returns. As has been noted in the literature, the smaller size and higher $B E / M E$ portfolios continue to generate economically significant alpha estimates, even after adjusting for market risk. When we add the innovations of SMB and HML risk factors in the model, the alpha estimate becomes insignificantly distinguishable from zero for small-size and high$B E / M E$ stocks. We find that the slope estimates (not reported) of all three common risk factors innovations (i.e., $\hat{u}_{t}^{S M B}, \hat{u}_{t}^{H M L}, \hat{u}_{t}^{M O M}$ ) shows a clear pattern. For example, for the $3 F$ model, $\hat{u}_{t}^{S M B}$ becomes significant for 17 out 25 portfolios and $\hat{u}_{t}^{H M L}$ becomes significant for 21 out 25 portfolios. For

\footnotetext{
${ }^{4}$ Note that, in our empirical tests, each representative asset $(i j)$ is a portfolio sorted by $i$ th size and $j$ th $B E / M E$ ratio. Therefore, various common investment styles such as value (high- $B E / M E$ portfolio), growth (low- $B E / M E$ portfolio), small-cap (small$M E$ portfolio), and large-cap (big- $M E$ portfolio) are well represented in our sample.

${ }^{5}$ It is important to note that, in our sample the size premium is statistically insignificant $0.29 \%$ per month whereas the value premium is $0.51 \%$ per month, which is statistically distinguishable from zero.

${ }^{6}$ When we combine the portfolio mean and standard deviation, the Sharpe ratio tend to be consistently higher for small-size and high- $B E / M E$ portfolios.
} 
the $4 \mathrm{~F}$ model, the innovation in momentum factor displays the lowest number (14 out of 25 portfolios) of statistical significance. The slope of innovation in GIP (i.e., $\hat{u}_{t}^{G I P}$ in CRR+1F model) becomes significant for 18 out of 25 portfolios. If we replace the innovations to SMB and HML by the actual returns on the SMB and HML, the results are marginally different, thereby indicating that the Fama-French factors and their innovations are good proxies for each other.

Altogether, the reported results in Table 1 suggests that for the 3F model, the alpha spread between the value and growth stocks for the biggest size quintiles becomes $-0.35 \%$. The same estimate for the $4 \mathrm{~F}$ model is $-0.11 \%$. Within the highest $B E / M E$ quintile, we observe three intercepts that are small and insignificantly different from zero in the presence of the Fama-French factors innovations. The same is not true for the smallest size quintile portfolios. The value premium disappears for bigger size stocks. Large value and small growth stocks underperform. The implication is that after the incorporation of characteristic-based factor innovations, there is a lower value premium for small-size stocks and a smaller growth premium for big-size stocks. We also look at the root mean square alpha and the mean absolute alpha separately for various models of Table 1 . The root mean square alphas for the 3F and 4F models are much smaller than for the $1 \mathrm{~F}$ model. For the mean absolute alpha, the $1 \mathrm{~F}$ model produces the highest value $^{7}$.

In Table 2 we present the basic first-order VAR regression results, which we utilize to generate the timeseries loadings of each of our testing assets. Our application of a full VAR to a six-equation model suggests that the coefficients in all equations are jointly significant at the $1 \%$ level. Only one lag of each variable is used in each equation. In the equation for $M k t r f_{t}$, except $U T S_{t-1}$ and $U P R_{t-1}$, the other coefficients are significant at least at the $10 \%$ level. In the equation for $G I P_{t}$, the coefficients of $G I P_{t-1}$, $U T S_{t-1}$ and $U P R_{t-1}$ remain highly significant at the $5 \%$ level. The VAR parameter estimates imply that $G I P_{t}$ does not appear to be explained by $M k t r f_{t-1}$. The spread in yields, rather than aggregate stock returns, appear to explain a substantial portion of the time-series variation in GIP8. Interestingly, there is bidirectional causality between excess market returns and unexpected changes in price level. The slope estimate of $M k t r f_{t-1}$ is significantly positive (at the $1 \%$ level) in the equation for $U I_{t}$ and $D E I_{t}$, and significantly negative (at the $5 \%$ level) in the equation for $U T S_{t}$ and $U P R_{t}$. As has been documented in

\footnotetext{
${ }^{7}$ In order to test if all the intercepts are zero simultaneously, we employ F- test statistics developed by Gibbons, Ross, and Shanken (1989), also known as the GRS test. We immediately see that for the market model the GRS test statistic generates a significant value of 4.67 ( $\mathrm{p}$-value=0.000). The same is true for the GRS statistic generated by the 3F and 4F specifications alpha estimates ( $\mathrm{F}=3.14$ and $\mathrm{F}=3.02$ respectively). Similarly, the simple CRR model as well as a combination of CRR and $1 \mathrm{~F}$ model's alpha estimates produces GRS F-test statistics of 3.43 and 3.37 respectively.

${ }^{8}$ It is important to note that there is a high rolling correlation (of magnitude 0.85) between our GIP innovation and the output gap measure of Cooper and Priestley (2009).
} 
the literature (Chen, Roll and Ross (1986)), there appears to be a statistically significant relationship between aggregate stock returns and real economic activity. The equations for both $U T S_{t}$ and $U P R_{t}$ produce the highest $\bar{R}^{2}$ of 0.94 and the equation for $D E I_{t}$ yields the lowest root-mean-squared-error of 0.09. We also perform a test for normality using the single-equation and joint Jarque-Bera statistics (not reported) and neither of them reject the null hypothesis that the disturbances in all the VAR equations are normally distributed.

Therefore, our preliminary results suggest that even though the market risk itself cannot explain the timeseries variability of the value premium, aggregate economic factors innovations may complement the story. In other words, there might be some types of risk other than the market proxy associated with small-size and high-BE/ME stocks, as predicted by Fama and French $(1993,1996)$ and a large number of authors. Without the incorporation of these other risks, portfolio evaluation techniques can be misleading. The aggregate economic factor innovations may play a supplementary role in improving the risk characterization of our testing assets, and without their incorporation the characterization of value-growth stocks is rather limited. As the innovations in GIP act like a potential business cycle-related state variable, similar to Guidolin, McMillan, and Wohar (2013), we can argue that the time-variation in the size and value premium is linked to the business cycle. In the next subsection we provide a framework for measuring the effectiveness of our methodology in the cross-sectional analysis.

\subsection{Portfolio level cross-sectional results}

The above empirical evidence raises an obvious question: Does innovation in GIP factor loading really explain the variation in the cross-sectional returns of all 25 portfolios? We answer that question by using the Fama-MacBeth (1973) cross-sectional regression (CSR) approach detailed in section 3. The estimation results from various versions of equation (5) are presented in Table 3. The CSR results show that a variable such as innovation in GIP goes a long way toward explaining the cross-sectional return variability of the 25 portfolios. When used alone, the single-factor GIP innovation beta explains a small

part of the cross-sectional differences in the 25 portfolio returns. In specification 1, the average $\bar{R}^{2}$ is low (18\%), but the estimated intercept is not significant at the $5 \%$ level (using robust Shanken t-statistic). The premium associated with the innovation in GIP is significantly positive $(0.43 \%)$, and under the errors-invariable correction, the Shanken t-statistic for the hypothesis $H_{0}: \gamma_{\widehat{u}}^{G I P}=0$ becomes 2.70, which is significant at least at the $5 \%$ level.

Adding four other CRR risk factors innovations (i.e., specification 2) improves the average $\bar{R}^{2}$ to 32\%, and the price of GIP innovation risk becomes 0.37 (Shanken t-statistic = 2.58). The corresponding CSR 
estimation result shows that the innovations in UI and UTS are positively priced, and the innovations in $D E I$ and $U P R$ are negatively priced. Only $U T S$ and $U P R$, however, are statistically significant (at the $10 \%$ level) in the cross-section ${ }^{9}$. Inclusion of the market factor in the pricing equation (as shown in specification 3) improves the overall explanatory power (average $\bar{R}^{2}$ increases to $44 \%$ ), but it does not drive out the role of the GIP innovation beta. Compared to the base model, the intercepts of the multifactor CSR models 2 and 3 are zero, as none of the t-statistics using Shanken's adjustment are significant at the $5 \%$ or better confidence level.

In order to investigate the influence of Fama-French factors on the aggregate risk innovations, we also include the innovations of SMB and HML in both the time-series and the cross-sectional analysis. Even in the presence of $\hat{\beta}_{\widehat{u}^{S M B}}$ and $\hat{\beta}_{\widehat{u}^{H M L}}$, the loading on $\hat{\beta}_{\widehat{u}^{G I P}}$ continues to be an important determinant of average portfolio returns. The Shanken t-statistics for the hypothesis $H_{0}: \gamma_{\widehat{u}}^{G I P}=0$ (against $H_{1}: \gamma_{\widehat{u}}^{G I P} \neq$ 0 ) are 2.42 and 2.31, for CSR specifications 4 and 5 respectively. The price of risk related to the size and value factor innovations are not significant at the 5\% level. For specification 5, the zero intercept hypothesis of the CSR is rejected only at the $10 \%$ level using the Fama-MacBeth t-statistic. Both facts that the estimated market risk premium is negative, and that the loadings on the Fama-French factor innovation are not significant in the cross-section - are consistent with previous studies (see e.g., Fong (2012), Lettau and Ludvigson (2001), Maio and Santa-Clara (2013), and Petkova (2006)) ${ }^{10}$. Therefore, our results suggest that the innovation in GIP, a close proxy for macroeconomic risk, is capturing a part of the cross-sectional return predictability of size- and book-to-market-sorted portfolios ${ }^{11}$. Consistent with rational asset pricing, the price of higher exposure to aggregate risk related to GIP surprises is positive.

\subsection{Measuring the role of innovation in aggregate risk at the individual stock level}

So far, our findings are based on a portfolio-level analysis and it is not clear whether the results are defendable for individual stocks. To investigate that issue, in this subsection we perform an individual

\footnotetext{
${ }^{9}$ We note that the counterparts of UTS and UPR in Petkova (2006), which the author refers as TERM and $D E F$ respectively, are slightly different. In Petkova (2006, Table II and V), only the TERM innovation beta is significant at the 1\% level, while DEF is not significant at all. Our results using the sample period July 1963 to December 2001 (not reported) correspond to Petkova’s (2006) results.

${ }^{10}$ We also replicate the cross-sectional regressions using two type of first-stage rolling regressions - five year rolling window and reverse recursive window regressions. Those results are consistent with what we observe in Table 3.

${ }^{11}$ It is important to note that in the literature numerous studies have analyzed the ability of macroeconomic factors to price the cross-section of U.S. returns. There is a consensus that macroeconomic risks do not explain the value premium (Fong 2012). While many of the existing studies have not explicitly looked at innovations in the macroeconomic factors, some of them, including Petkova (2006) and Aretz et al.(2010), have. The general conclusions from these studies seem to be that slight variations in the empirical setup can greatly influence empirical findings. That is, although Aretz et al. (2010) find that economic growth risk helps to price characteristic-sorted portfolios, a similar factor never attracts statistical significance in Petkova (2006).
} 
stock-level analysis to evaluate the role of GIP innovation risk for individual stocks. In order to conduct such an experiment, we utilize various one and two-dimensional portfolios.

We start with a set of one-dimensional portfolios of stocks based on 10 deciles of GIP innovations beta. For each month $t$, we first estimate the GIP innovation beta using the past 36 to 60 months of data (as available) for each stock. The estimated slope coefficient of the GIP innovation is then used to construct betas. At least 36 observations are required for each time-series regression at month $t$ based on the data up through month $t-1$. The corresponding monthly average excess returns of all 10 decile portfolios and long-short portfolio are reported in Panel A of Table 4. The second set of one-dimensional portfolios are based on $B E / M E$ and obtained from Ken French. The correspondingly monthly returns are reported in Panel B.

We also construct three sets of alternative two-dimensional portfolios of stocks, which are double-sorted (both directions) by $B E / M E$ and GIP innovations beta. For the first set, at the end of each June, stocks are sorted into two $B E / M E$ groups (low and high) using the median NYSE breakpoint. The stocks in each group are then sorted into two subgroups (low and high) based on the median value of the GIP innovation beta. The entire double-sorting results in four value-weighted portfolios, the average monthly returns of which are then computed. The portfolios are formed annually and the positions are held over the following 12 months. The resulting summary of average monthly excess returns is reported in Panel C (as Case 1). In the second construction, the order of sorting is reversed: stocks are sorted first into groups by the GIP innovation beta, and then into subgroups by $B E / M E$. In Panel $\mathrm{C}$, the results of the second set of portfolios are reported as Case 2.

In the third set of double-sorted portfolios, we perform an independent sorting to construct another set of two-dimensional portfolios based on $B E / M E$ and GIP innovation betas ${ }^{12}$. Unlike in Case 1 and 2, we now use both sorting criteria (dimensions) based on $B E / M E$ and GIP innovation beta independently. We simultaneously sort all the stocks into low and high groups based on the median GIP innovation beta, and into low and high groups based on the median $B E / M E$ breakpoint. The key is that we conduct both sorting processes independently and in parallel. As a result, we construct four new portfolios, which are based on unconditional double-sorting and different from the previous two sets of portfolios. In Panel C, the monthly average returns of the new portfolios are reported as Case $3^{13}$.

\footnotetext{
${ }^{12}$ We thank an anonymous referee for suggesting the independent sorting.

${ }^{13}$ Compared to the unconditional double-sorting, the average number of firms (not reported) for each portfolio constructed by our two conditional double-sorting shows very little variation. For example, for portfolios sorted first by $B E / M E$ and then by the GIP innovation beta (Case 1), the low- $B E / M E$ group contains 725.1 firms on average, and the high- $B E / M E$ group contains an
} 
The results in Panel A show that a sorting based on GIP innovation beta does portray an intuitive picture of the average portfolio returns. In general, firms in higher GIP innovation beta deciles have higher returns. The highest GIP beta decile portfolio earns 1.19\% per month and the return is significant at the 1\% level. Even though the average returns doesn’t display a monotonically increasing trend from low to high GIP beta deciles, on an average, stocks in the low GIP innovation beta deciles commands significantly lower returns. The high-minus-low portfolio, which holds the highest GIP beta portfolio and shorts the lowest GIP beta portfolio, generates a premium of $0.54 \%$ per month. For the $B E / M E$-sorted portfolios, shown in Panel B, the average return trend is rather transparent and supports what is already known in the existing literature. Value stocks dominate growth stocks over the entire sample period. The average long-short portfolio based on $\mathrm{BE} / \mathrm{ME}$ is $0.51 \%$ per month, which is slightly smaller than its Panel A counterpart. As the constituents of two sets of decile portfolios are different, the findings are not surprising.

In order to understand the nature of the risk adjusted return of GIP innovation beta decile portfolios, we use the market model and the Fama-French 3F model and evaluate at the intercept and slope estimates in time-series regressions. The results, reported in Table A1 of the appendix, suggest that market beta alone is not successful in explaining the abnormal returns. The size and value factors, on the other hand, capture a part of the systematic risk. The magnitude of the SMB slope estimate decreases from low to high GIP beta deciles, and that of HML increases from low to high GIP beta deciles. Unlike the market model, where all the intercepts are significant, the $3 \mathrm{~F}$ model results in risk adjusted returns that are not statistically significant for six deciles, even at the $10 \%$ level.

We consolidate the above findings by looking at the information content of our two-dimensional portfolios. In terms of average performance of various double-sorted portfolios, the portfolio of stocks within the low- $B E / M E$ group (i.e., Case 1) shows a $0.90 \%$ monthly return for the low-GIP innovation beta and a $1.47 \%$ monthly return for the high-GIP innovation beta group. For the high- $B E$ / $M E$ group, the average return increases from $0.97 \%$ per month for the low-GIP innovation beta to an impressive $1.70 \%$ per month for the high-GIP innovation beta. Our first double sorting generates an average monthly value premium of $0.48 \%$ for the high-GIP innovation beta, and $0.15 \%$ for the low-GIP innovation beta. The return on the long-short portfolio using the GIP innovation beta is large (0.74\% per month) for the value category, and relatively small (0.40\%) for the growth category.

average of 644.7 firms. For the GIP innovation beta group, the smallest (largest) number of firms belongs to the high-GIP (lowGIP) innovation beta. In contrast, when we perform independent (unconditional) double-sort, the low- $B E / M E$ group and lowGIP innovation beta group contains the largest number of firms. Our results are not sensitive to equal-weighting or a concentration on NYSE stocks. Details are available upon request. 
In Case 2, when we reverse the portfolio sorting order, we observe some new findings. Among all four portfolios, the low- $B E / M E$ plus low-GIP innovation beta portfolio continues to generate the lowest average excess return (0.94\% per month). Both portfolios corresponding to the high-GIP innovation beta generate higher average monthly returns compared to their low-GIP innovation beta counterparts, although the differences are no longer economically large. We observe that the average excess return of the value group is now lower (1.18\% in Case 2 versus $1.34 \%$ in Case 1$)$, and that of the growth group is now slightly higher (1.11\% in Case 2 versus $1.02 \%$ in Case 1 ). The average spread in returns between value and growth portfolios goes down significantly for the high-GIP innovation beta category. Also, the average excess return of the low-GIP innovation beta group becomes discernibly higher (0.97\% per month in Case 2 as compared to $0.90 \%$ per month in Case 1).

Even though, by construction, the constituents of the third set of double-sorted portfolios in Panel C (i.e., Case 3) are slightly different, their average returns follow a pattern similar to Case 1 . The high- $B E / M E$ (low-BE / $M E)$ portfolio generates an average excess return of $1.17 \%(0.95 \%)$ per month. The long-short portfolio based on the GIP innovation beta generates an average return of $0.48 \%$ for the high- $B E / M E$ group and $0.38 \%$ for the low- $B E / M E$ group. There is a significant value premium for both low and high GIP innovation beta groups.

The most interesting finding in all three panels is the role of reverse sorting in the average spread of the long-short portfolios. For Case 2, when we move from low to high-GIP innovation beta portfolios, the average spread between the low and high- $B E / M E$ portfolios is in the range of 5 to 9 basis points and not significant at the $5 \%$ or better significance level. It is instructive that if the value-premium is indeed driven by the GIP innovation beta, the spread between value and growth portfolios after controlling for GIP innovation beta will be insignificant or significantly weakened. In Panel C of Table 4 we find evidence that this is indeed the case. Therefore, in sum, there is considerable predictive power in the GIP innovation in our sample, even at the individual stock level. Based on our results, the GIP innovation beta is helpful in dissecting the overall spread of the value premium.

\subsection{Cross-sectional regressions at the individual stock level}

In this last subsection, we evaluate the cross-sectional role of the GIP innovation beta by performing month-by-month cross-sectional regressions at the individual stock level during the period from July 1963 to June 2011. We use the standard Fama and MacBeth (1973) methodology to control the crosscorrelation in residuals. The observations are at a monthly frequency for all stocks listed on NYSEAMEX-NASDAQ. Following the existing studies in the literature, we control for several firm-specific characteristics. They are log of firm size or market capitalizations $\ln (M E)$, log of book-to-market ratio 
$\ln (B E / M E)$, short-term return reversal (Chan (2003)), and momentum (Jegadeesh and Titman (1993)).

For each month we run the following cross-sectional regressions

$$
R_{i, t}=\gamma_{0, t}+\sum_{k=1}^{K} \gamma_{k, t} X_{k, i, t}+u_{i, t}, i=1,2, \ldots, N_{t}, t=1,2, \ldots, T,(6)
$$

where $R_{i, t}$ is the realized return on stock $i$ in month $t, X_{k, i, t}$ includes the set of explanatory variables such as market beta, CRR factors innovations, and firm-level characteristics. For each month $t=1,2, \ldots, T, N_{t}$ is the total number of stocks that varies from month to month. We calculate the t-statistic by the average slope divided by its time-series standard error.

In Table 5 we present the familiar, standard set of CSR specifications. In specification 1, consistent with existing literature, the market beta carries a positive but statistically insignificant coefficient of 0.032 (tstatistic equal to 0.77 ). In specification 2, when we use the GIP innovation beta, the corresponding slope coefficient estimate turns out to be small, positive, and significant $\left(\hat{\gamma}_{\widehat{u}^{G I P}}=0.041, \mathrm{t}=2.83\right)$ at the $1 \%$ level. When we include market as well as GIP innovation in our CSR (i.e., specification 3), the coefficient of the GIP innovation beta becomes lower (0.034) but remains significant $(\mathrm{t}=2.67)$ at the $1 \%$ level. In specifications 4 to 6 , we find that the role of $\widehat{u}^{G I P}$ is robust to controlling for other CRR factors innovations and two firm-specific characteristics. As has been found in other studies, in our sample, firm size is negatively related to average returns, and $B E / M E$ is positively related to average returns. The price of UTS innovation risk is significantly positive at the firm-level CSR. It is important to note that, Lu and Zhang (2008, Table 4) already show that the loading on GIP growth declines monotonically with size and increases monotonically with $B E / M E$. Our results therefore revalidate Lu and Zhang (2008) by using innovations to the factors rather than the factors themselves ${ }^{14}$. While the GIP innovation beta is not a sufficient statistic to explain the cross-section of stock returns, there is definitely a reward for holding stocks with high exposure to $\hat{u}^{G I P}$, which confirms our previous findings based on the sorting of individual stocks in Table 4. In the last 3 specifications, we control for short-term return reversal and momentum in the cross-section. At the end of each month, we estimate (6) by including $R_{i, t-1}$, which is the return of asset $i$ in month $t-1$, and and $\sum_{k=2}^{12} R_{i, t-k}$, which is the 11-month cumulative return of asset $i$ from $t-12$ and $t-2$, as additional explanatory variables. The results - reported in model 7 through 9 - suggest that in the cross-section the past-month return and the past-year return are not very significant across these assets.

\footnotetext{
${ }^{14}$ In addition to the full sample betas, similar to Fama and French (1993) we also implement a rolling window version of the CSR, which provides a robustness test against forward-looking bias. For that we use beta at December of time $t-1$, as well as size and $B E / M E$ at Decemebr of time $t-1$, and explain excess returns from July of $t$ to June of $t+1$. When we use the rolling monthly coefficients and standard errors for statistical inferences, the results are qualitatively similar to the full sample counterpart. We thank an anonymous referee for suggesting the rolling window estimation.
} 
Two natural questions might be: (1) Which stocks have statistically significant GIP innovation betas? and, (2) Why do stocks with high GIP innovation betas produce higher average returns? We find that the exposure to nonfinancial market-based variables such as GIP innovations varies widely across industries and over time. In the mid-cap (with market capitalization of $\$ 2$ billion to $\$ 15$ billion) value category, firms in consumer discretionary, industrials, information technology, and materials have the highest GIP innovation beta. In the large-cap (with market capitalization of $\$ 15$ billion to $\$ 50$ billion) value category, the largest GIP innovation beta firms are in energy, health care, industrials, information technology, and telecommunication services. In the small-cap (with market capitalization under $\$ 2$ billion) value category, firms in materials and consumer staples display the highest sensitivity to GIP innovation. A large number of mid- and large-cap growth firms with the highest sensitivity to GIP innovation are energy firms involved in oil, gas, and coal extraction activities. Typically, the value firms are much more sensitive to change in GIP innovation, which essentially is based on production related data. This sensitivity contributes to a cross-sectional relationship between average returns and $\hat{u}^{G I P}$ betas. Small-cap growth firms are much more sensitive to changes in GIP but less sensitive to GIP innovations and their average returns do not respond to changes in $\hat{u}^{G I P}$ betas in the cross-section. It is well-established that the value premium is countercyclical and the value stocks become particularly risky during economic downturns. Following Cooper and Priestley (2009), we can argue that the GIP innovation is a classical business cycle variable and may contain information about the variation in return differences between value and growth stocks over the business cycle. Our findings also indirectly support the idea of Guidolin, McMillan, and Wohar (2013), that the time-variation in stock return predictability is related to the information content of monthly GIP, which is essential for the characterization of the business cycle. The GIP innovation beta, therefore, may capture a part of time-varying risk, which further is related to the countercyclical variation of the value premium.

\section{Conclusions}

In this study, we revisit the role of innovation in economic fundamentals. We test whether innovation in aggregate risk, interpolated from a vector autoregressive system that contains the Chen, Roll and Ross (1986) five factors, is a common factor in cross-sectional asset returns. We develop a framework, both at the portfolio and individual stock level, which evaluates the cross-sectional roles of innovations in aggregate predictive variables. Our results illustrate that growth in industrial production plays a nontrivial role in the risk characterization of the value-growth stocks. We show that innovation in growth in industrial production, a potential business cycle-related state variable, is an important cross-sectional determinant of average returns of portfolios and individual stocks. One can extend our results in various 
directions. It would be interesting to see whether our results are defendable by using additional test assets (such as momentum, reversal, price-to-earnings ratio etc.) to estimate the price of risk of the innovations. Another topic for exploration is the role of innovations risk in other countries' stock returns. We leave those issues for future research. 


\section{References:}

Aretz, K., Bartram, A, M., and Pope, P.F. 2010. Macroeconomic risk and characteristic-based factor models. Journal of Banking and Finance, 34(6), 1383-1399.

Arshanapalli, B., Fabozzi, F. J., Nelson, W. 2006. The value, size, and momentum spread during distressed economic periods, Finance Research Letters, 3(4), 244-252.

Asness, C. S., Moskowitz, T. J., and Pedersen, L. H. (2013).Value and momentum everywhere. Journal of Finance, 68(3), 929-985.

Brennan, M. J., A. Wang, Y. Xia, 2004. Estimation and test of a simple intertemporal capital asset pricing model. Journal of Finance, 59(4), 1743-1776.

Campbell, J.Y. 1996. Understanding risk and return. Journal of Political Economy, 104(2), 298-345.

Campbell, J.Y., Vuolteenaho, T. 2004. Inflation illusion and stock prices. American Economic Review, 94(2), 19-23.

Carhart, M. M. 1997. On Persistence in Mutual Fund Performance. Journal of Finance, 52, 57-82.

Chan, W. S. 2003. Stock price reaction to news and no-news: drift and reversal after headlines. Journal of Financial Economics, 70(2), 223-260.

Chen, N. F., Roll, R., and Ross, S.A. 1986. Economic forces and the stock market, Journal of Business, 59(3), 383-403.

Choi, J. 2013. What drives the value premium?: The role of asset risk and leverage, Review of Financial Studies, 26(11), 2845-2875.

Cochrane, J. H. 2005. Asset Pricing. Princeton University Press, Princeton, NJ.

Cooper, I., Priestley, R. 2008. Time-varying risk premiums and the output gap, Review of Financial Studies, 22(7), 2801-2833.

Engle, R. F., Ghysels, E., and Sohn, B. 2013. Stock Market Volatility and Macroeconomic Fundamentals, Review of Economics and Statistics, 95(3), 776-797.

Fama, E. F., French, K. R. 1993. Common risk factors in the returns on stocks and bonds, Journal of Financial Economics, 33(1), 3-56.

Fama, E. F., French, K. R. 1996. Multifactor explanations of asset pricing anomalies, Journal of Finance, 51(1), 55-84.

Fama, E. F., French, K. R. 2012. Size, value, and momentum in international stock returns, Journal of Financial Economics, 105(3), 457-472.

Fama E. F., MacBeth J. 1972. Risk, return, and equilibrium: Empirical tests, Journal of Political Economy, 81(3), 607-636. 
Fong, W. M. 2012. Do expected business conditions explain the value premium, Journal of Financial Markets, 15(2), 181-206.

Gibbons, M. R., Ross. S. A., and Shanken, J. 1989. A test of the efficiency of a given portfolio. Econometrica, 57(5): 1121-1152.

Guidolin, M., McMillan, D. G., Wohar, M. E. 2013. The varying stock return predictability: Evidence from US sectors, Finance Research Letters, 10(1), 34-40.

Hwang, S., Rubesam, A. 2013. A behavioral explanation of the value anomaly based on time-varying return reversals, Journal of Banking and Finance, 37(7), 2367-2377.

Jegadeesh, N., and Titman, S. 1993. Returns to buying winners and selling losers: Implications for stock market efficiency, Journal of Finance, 48(1), 65-91.

Knez, P. J., Ready, M. J. 1997. On the robustness of size and book-to-market in cross sectional regressions, Journal of Finance, 52(4), 1355-1382.

Krishnan, C.N.V., Petkova, R., Ritchken, P. 2009. Correlation risk. Journal of Empirical Finance, 16(3), 353-367.

Lettau, M., Ludvigson, S. 2001. Consumption, aggregate wealth, and expected stock returns. Journal of Finance, 61(3), 815-849.

Liu, L. X., Zhang, L. 2008. Momentum profits, factor pricing, and macroeconomic risk, Review of Financial Studies, 21(6), 2417-2448.

Maio, P. F., Santa-Clara, P. 2013. The Fed and stock market anomalies. Available at SSRN:

http://ssrn.com/abstract=1986787 or http://dx.doi.org/10.2139/ssrn.1986787.

Merton, R. 1973. An intertemporal capital asset pricing model. Econometrica, 41(5), 867-887.

Novy-Marx, R. 2013. The other side of value: The gross profitability premium, Journal of Financial Economics, 108(1), 1-28.

Petkova, R. 2006. Do the Fama-French factors proxy for innovations in predictive variables? Journal of Finance, 61(2), 581-612.

Shanken, J. 1992. On the Estimation of Beta-Pricing Models. Review of Financial Studies, 5(1), 1-33. 
Table 1: Summary statistics for the 25 size- and book-to-market-sorted portfolios (January 1962 and December 2011)

\begin{tabular}{|c|c|c|c|c|c|c|}
\hline \multirow[b]{2}{*}{$\begin{array}{l}\text { Size } \\
\text { Quintiles }\end{array}$} & \multicolumn{6}{|c|}{ Book-to-market equity (BE/ME) quintiles } \\
\hline & Low & 2 & 3 & 4 & High & $\begin{array}{l}\text { Value } \\
\text { Premium }\end{array}$ \\
\hline & & Average & Excess $\mathrm{Re}$ & turns & & \\
\hline Small & 0.22 & $0.71 * *$ & $0.77 * * *$ & $0.94 * * *$ & $1.08 * * *$ & 0.86 \\
\hline 2 & 0.38 & $0.64 * *$ & $0.85^{* * *}$ & $0.88 * * *$ & $0.96 * * *$ & 0.58 \\
\hline 3 & 0.39 & $0.69 * * *$ & $0.71 * * *$ & $0.80 * * *$ & $1.01 * * *$ & 0.62 \\
\hline 4 & $0.49 * *$ & $0.50 * *$ & $0.64 * * *$ & $0.79 * * *$ & $0.79 * * *$ & 0.30 \\
\hline \multirow[t]{2}{*}{ Big } & $0.37 *$ & $0.45 * *$ & $0.43 * *$ & $0.50 * * *$ & $0.54 * * *$ & 0.17 \\
\hline & \multicolumn{5}{|c|}{ 1F model alpha } & \\
\hline Small & $-0.38 *$ & 0.19 & $0.31 * *$ & $0.51^{* * *}$ & $0.62 * * *$ & 1.00 \\
\hline 2 & -0.21 & 0.15 & $0.40 * * *$ & $0.45 * * *$ & $0.49 * * *$ & 0.70 \\
\hline 3 & -0.16 & $0.22 * *$ & $0.28 * * *$ & $0.39 * * *$ & $0.58 * * *$ & 0.74 \\
\hline 4 & -0.02 & 0.04 & $0.21 * *$ & $0.38 * * *$ & $0.36 * * *$ & 0.38 \\
\hline \multirow[t]{2}{*}{ Big } & -0.04 & 0.06 & 0.07 & 0.15 & 0.17 & 0.21 \\
\hline & \multicolumn{4}{|c|}{ 3F model alpha } & & \\
\hline Small & $-0.43 * * *$ & -0.02 & 0.02 & $0.14 * *$ & $0.13^{* *}$ & 0.56 \\
\hline 2 & $-0.16^{* *}$ & -0.04 & $0.11 *$ & 0.07 & -0.01 & 0.15 \\
\hline 3 & -0.06 & 0.06 & 0.01 & 0.04 & 0.13 & 0.16 \\
\hline 4 & $0.13^{*}$ & -0.08 & -0.03 & 0.08 & -0.06 & -0.19 \\
\hline \multirow[t]{2}{*}{ Big } & $0.17 * * *$ & 0.05 & -0.04 & $-0.10 *$ & $-0.18^{*}$ & -0.35 \\
\hline & \multicolumn{5}{|c|}{ 4F model alpha } & \\
\hline Small & 0.02 & $0.12 *$ & 0.04 & $0.14 * *$ & 0.02 & 0.00 \\
\hline 2 & -0.07 & -0.05 & 0.06 & 0.01 & -0.05 & 0.02 \\
\hline 3 & -0.05 & -0.01 & -0.06 & -0.01 & 0.10 & 0.15 \\
\hline 4 & $0.14 *$ & -0.13 & -0.08 & 0.08 & -0.06 & -0.26 \\
\hline \multirow[t]{2}{*}{ Big } & 0.09 & 0.00 & -0.01 & -0.06 & -0.02 & -0.11 \\
\hline & \multicolumn{5}{|c|}{ CRR +1 F model alpha } & \\
\hline Small & $-0.60 * *$ & -0.02 & 0.06 & 0.26 & 0.24 & 0.84 \\
\hline 2 & $-0.33 *$ & 0.01 & 0.24 & $0.32 * *$ & $0.34 * *$ & 0.67 \\
\hline 3 & -0.22 & 0.11 & 0.19 & $0.30 * *$ & $0.46 * * *$ & 0.68 \\
\hline 4 & -0.04 & -0.03 & 0.18 & $0.37 * * *$ & $0.28 *$ & 0.32 \\
\hline Big & -0.01 & 0.11 & 0.18 & 0.22 & 0.19 & 0.20 \\
\hline
\end{tabular}

Note: This table shows the average excess returns and alphas of the 25 size- and book-to-market-sorted portfolios between January 1962 and December 2011. For 1F model, the alphas are the intercepts from the time-series regression $R_{i, t}=\beta_{0, i}+$ $\beta_{M, i} R_{M, t}+\varepsilon_{i, t}$. For 3F model, the alphas are the intercepts from the time-series regression $R_{i, t}=\beta_{0, i}+\beta_{M, i} R_{M, t}+$ $\beta_{\widehat{u}^{S M B}, i} \hat{u}_{t}^{S M B}+\beta_{\widehat{u}^{H M L}, i} \hat{u}_{t}^{H M L}+\varepsilon_{i, t}$. For $4 \mathrm{~F}$ model, the alphas are the intercepts from the time-series regression $R_{i, t}=\beta_{0, i}+$ $\beta_{M, i} R_{M, t}+\beta_{\widehat{u}^{S M B}, i} \hat{u}_{t}^{S M B}+\beta_{\widehat{u}^{H M L}, i} \hat{u}_{t}^{H M L}+\beta_{\widehat{u}^{M O M}, i} \hat{u}_{t}^{M O M}+\varepsilon_{i, t}$. For CRR+1F model, the alphas are the intercepts from the timeseries regression $R_{i, t}=\beta_{0, i}+\beta_{M, i} R_{M, t}+\beta_{\widehat{u}^{U I}, i} \hat{u}_{t}^{U I}+\beta_{\widehat{u}^{D E I}, i} \hat{u}_{t}^{D E I}+\beta_{\widehat{u}^{U T S}, i} \hat{u}_{t}^{U T S}+\beta_{\widehat{u}^{U P R}, i} \hat{u}_{t}^{U P R}+\beta_{\widehat{u}^{G I P}, i} \hat{u}_{t}^{G I P}+\varepsilon_{i, t} \cdot R_{i, t}$ is the excess return of asset $i$ at time $t . M$ is the ex-post excess market return which is equal to the value-weighted CRSP portfolio in excess of the 3-month Treasury bill rate. $U I_{t}=I_{t}-E\left[I_{t} \mid t-1\right]$ where $I_{t}=\ln \left(C P I S A_{t}\right)-\ln \left(C P I S A_{t-1}\right)$, and $C P I S A_{t}$ is the seasonally adjusted Consumer Price Index from the Labor Bureau of Statistics; DEIt $=E\left[I_{t+1} \mid t\right]-E\left[I_{t} \mid t-1\right]$, where $E\left[I_{t} \mid t-1\right]=R_{f, t}-E\left[R h o_{t} \mid t-1\right], R h o_{t}=R_{f, t}-I_{t}, E\left[R h o_{t} \mid t-1\right]=\left(R_{f, t-1}-I_{t-1}\right)-\left(\hat{v}_{t}+\hat{\varphi} \hat{v}_{t-1}\right)$, and $R_{f, t}$ is the onemonth T-bill rate; UTS is defined as a 20-year - 1-year treasury yield from the FRED database at the Federal Reserve Bank of St. Louis; and $U P R$ is defined as the BAA-AAA yield from the FRED database at Federal Reserve Bank of St. Louis; $G I P_{t}=$ $\ln \left(I P_{t}\right)-\ln \left(I P_{t-1}\right)$, where $I P_{t}$ is the index of industry production in month $t$ from the FRED database at Federal Reserve Bank of St. Louis. SMB, HML, and $M O M$ are size, value, and momentum factors respectively, obtained from Ken French. Coefficients marked with $* * *, * *$, and $*$ are significant at the $1 \%, 5 \%$, and $10 \%$ level respectively. 
Table 2: Vector autoregressive regression results (January 1962 - December 2011)

\begin{tabular}{|c|c|c|c|c|c|c|c|c|c|}
\hline \multirow[b]{2}{*}{$\begin{array}{l}\text { Dependent } \\
\text { Variable } \\
\end{array}$} & \multirow[b]{2}{*}{ Constant } & \multirow[b]{2}{*}{$M k t r f_{t-1}$} & \multicolumn{3}{|c|}{ Independent Variables } & \multirow[b]{2}{*}{$U T S_{t-1}$} & \multirow[b]{2}{*}{$U P R_{t-1}$} & \multirow[b]{2}{*}{$\bar{R}^{2}$} & \multirow[b]{2}{*}{ RMSE } \\
\hline & & & $G I P_{t-1}$ & $U I_{t-1}$ & $D E I_{t-1}$ & & & & \\
\hline$M k t r f_{t}$ & $\begin{array}{l}-0.55 \\
(-1.13)\end{array}$ & $\begin{array}{l}0.08 * * \\
(2.08)\end{array}$ & $\begin{array}{l}0.44^{*} \\
(1.69)\end{array}$ & $\begin{array}{l}1.99 * * \\
(1.95)\end{array}$ & $\begin{array}{l}-8.12 * * * \\
(-3.23)\end{array}$ & $\begin{array}{l}0.19 \\
(1.52)\end{array}$ & $\begin{array}{l}0.58 \\
(1.37)\end{array}$ & 0.04 & 4.49 \\
\hline$G I P_{t}$ & $\begin{array}{l}0.50 * * * \\
(6.59)\end{array}$ & $\begin{array}{l}0.01 \\
(0.94)\end{array}$ & $\begin{array}{l}0.24 * * * \\
(5.98)\end{array}$ & $\begin{array}{l}0.08 \\
(0.51)\end{array}$ & $\begin{array}{l}0.60 \\
(1.55)\end{array}$ & $\begin{array}{l}0.05^{* *} \\
(2.38)\end{array}$ & $\begin{array}{l}-0.37 * * * \\
(-5.75)\end{array}$ & 0.17 & 0.69 \\
\hline$U I_{t}$ & $\begin{array}{l}-0.00 \\
(-0.03)\end{array}$ & $\begin{array}{l}0.01 * * * \\
(3.61)\end{array}$ & $\begin{array}{l}0.01 \\
(0.72)\end{array}$ & $\begin{array}{l}0.35^{* * *} \\
(6.42)\end{array}$ & $\begin{array}{l}-0.63 * * * \\
(-4.71)\end{array}$ & $\begin{array}{l}0.01 \\
(1.00)\end{array}$ & $\begin{array}{l}-0.01 \\
(-0.42)\end{array}$ & 0.09 & 0.24 \\
\hline$D E I_{t}$ & $\begin{array}{l}0.00 \\
(0.01)\end{array}$ & $\begin{array}{l}0.00 * * * \\
(4.16)\end{array}$ & $\begin{array}{l}0.01^{* *} \\
(2.29)\end{array}$ & $\begin{array}{l}0.16^{* * *} \\
(7.24)\end{array}$ & $\begin{array}{l}-0.42 * * * \\
(-7.87)\end{array}$ & $\begin{array}{l}0.00 \\
(0.27)\end{array}$ & $\begin{array}{l}-0.01 \\
(-0.67)\end{array}$ & 0.13 & 0.09 \\
\hline$U T S_{t}$ & $\begin{array}{l}0.01 \\
(0.17)\end{array}$ & $\begin{array}{l}-0.01^{* *} \\
(-2.09)\end{array}$ & $\begin{array}{l}-0.08 * * * \\
(-4.13)\end{array}$ & $\begin{array}{l}0.17^{* *} \\
(2.05)\end{array}$ & $\begin{array}{l}-0.50 * * \\
(-2.49)\end{array}$ & $\begin{array}{l}0.97 * * * \\
(95.93)\end{array}$ & $\begin{array}{l}0.06^{* * *} \\
(1.71)\end{array}$ & 0.94 & 0.36 \\
\hline$U P R_{t}$ & $\begin{array}{l}0.05 * * * \\
(4.27) \\
\end{array}$ & $\begin{array}{l}-0.01 * * * \\
(-5.97) \\
\end{array}$ & $\begin{array}{l}-0.02 * * * \\
(-2.39) \\
\end{array}$ & $\begin{array}{l}-0.08 * * * \\
(-3.02) \\
\end{array}$ & $\begin{array}{l}0.07 \\
(1.04) \\
\end{array}$ & $\begin{array}{l}-0.01 * * * \\
(-2.21) \\
\end{array}$ & $\begin{array}{l}0.96 * * * \\
(90.86) \\
\end{array}$ & 0.94 & 0.11 \\
\hline
\end{tabular}

Note: This table reports estimates from a multivariate vector autoregressive model as discussed in the main text. $M k t r f$ is the ex-post excess market return which is equal to the value-weighted CRSP portfolio in excess of the 3-month Treasury bill rate. $G I P_{t}=\ln \left(I P_{t}\right)-\ln \left(I P_{t-1}\right)$, where $I P_{t}$ is the index of industry production in month $t$ from the FRED database at Federal Reserve Bank of St. Louis; $U I_{t}=I_{t}-E\left[I_{t} \mid t-1\right]$ where $I_{t}=\ln \left(C P I S A_{t}\right)-\ln \left(C P I S A_{t-1}\right)$, and $C P I S A_{t}$ is the seasonally adjusted Consumer Price Index from the Labor Bureau of Statistics; DEIt $=E\left[I_{t+1} \mid t\right]-E\left[I_{t} \mid t-1\right]$, where $E\left[I_{t} \mid t-1\right]=R_{f, t}-E\left[R h o_{t} \mid t-1\right], R h o_{t}=R_{f, t}-I_{t}, E\left[R h o_{t} \mid t-1\right]=\left(R_{f, t-1}-I_{t-1}\right)-\left(\hat{v}_{t}+\right.$ $\hat{\varphi} \hat{v}_{t-1}$ ), and $R_{f, t}$ is the one-month T-bill rate; UTS is defined as a 20-year - 1-year treasury yield from the FRED database at the Federal Reserve Bank of St. Louis; and $U P R$ is defined as the BAA-AAA yield from the FRED database at Federal Reserve Bank of St. Louis. The data are sampled monthly over the period Jan 1962 to Dec 2011 . z-statistics are reported in parenthesis. Coefficients marked with ***, **, and * are significant at the $1 \%, 5 \%$, and $10 \%$ level respectively. 
Table 3: Two-stage Fama-MacBeth (1973) cross-sectional regressions (January 1962 - December 2011, 600 months)

\begin{tabular}{|c|c|c|c|c|c|c|c|c|c|c|}
\hline Specification & $\gamma_{0}$ & $\gamma_{M k t r f}$ & $\gamma_{\widehat{u}^{U I}}$ & $\gamma_{\widehat{u}^{D E I}}$ & $\gamma_{\widehat{u}^{U T S}}$ & $\gamma_{\widehat{u}^{U P R}}$ & $\gamma_{\widehat{u}^{G I P}}$ & $\gamma_{\widehat{u}^{S M B}}$ & $\gamma_{\widehat{u}^{H M L}}$ & $A d j R^{2}$ \\
\hline $\begin{array}{l}\text { (1) Estimate } \\
\text { (FM t-stat) } \\
\text { [SH t-stat] }\end{array}$ & $\begin{array}{l}0.94 \\
(2.01)^{* *} \\
{[1.85]^{*}}\end{array}$ & & & & & & $\begin{array}{l}0.43 \\
(3.11)^{* * *} \\
{[2.70]^{* *}}\end{array}$ & & & 0.18 \\
\hline $\begin{array}{l}\text { (2) Estimate } \\
\text { (FM t-stat) } \\
\text { [SH t-stat] }\end{array}$ & $\begin{array}{l}0.71 \\
(1.79)^{*} \\
{[1.44]}\end{array}$ & & $\begin{array}{l}0.21 \\
(1.08) \\
{[0.70]}\end{array}$ & $\begin{array}{l}-0.15 \\
(-0.76) \\
{[-0.41]}\end{array}$ & $\begin{array}{l}0.54 \\
(2.45)^{* *} \\
{[2.02]^{* *}}\end{array}$ & $\begin{array}{l}-0.43 \\
k(-2.01)^{*} \\
\\
{[-1.78]^{*}}\end{array}$ & $\begin{array}{l}0.37 \\
*(3.02)^{* * *} \\
\\
{[2.58]^{* * *}}\end{array}$ & & & 0.32 \\
\hline $\begin{array}{l}\text { (3) Estimate } \\
\text { (FM t-stat) } \\
\text { [SH t-stat] }\end{array}$ & $\begin{array}{l}0.50 \\
(1.77)^{*} \\
{[1.64]}\end{array}$ & $\begin{array}{l}-0.40 \\
(-1.31) \\
{[-0.87]}\end{array}$ & $\begin{array}{l}0.24 \\
(1.21) \\
{[0.82]}\end{array}$ & $\begin{array}{l}-0.12 \\
(-0.62) \\
{[-0.33]}\end{array}$ & $\begin{array}{l}0.51 \\
(2.31)^{* *} \\
{[1.92]^{*}}\end{array}$ & $\begin{array}{l}-0.39 \\
(-1.93) * \\
{[-1.57]}\end{array}$ & $\begin{array}{l}0.30 \\
(2.71)^{* * *} \\
{[2.47]^{* * *}}\end{array}$ & & & 0.34 \\
\hline $\begin{array}{l}\text { (4) Estimate } \\
\text { (FM t-stat) } \\
\text { [SH t-stat] }\end{array}$ & $\begin{array}{l}0.57 \\
(1.95)^{*} \\
{[1.57]}\end{array}$ & $\begin{array}{l}-0.30 \\
(-1.19) \\
{[-0.66]}\end{array}$ & & & & & $\begin{array}{l}0.24 \\
(2.80)^{* * *} \\
{[2.42]^{* *}}\end{array}$ & $\begin{array}{l}0.38 \\
(1.81)^{*} \\
{[1.56]}\end{array}$ & $\begin{array}{l}0.48 \\
(2.02)^{* *} \\
{[1.82]^{*}}\end{array}$ & 0.38 \\
\hline $\begin{array}{l}\text { (5) Estimate } \\
\text { (FM t-stat) } \\
\text { [SH t-stat] }\end{array}$ & $\begin{array}{l}0.45 \\
(1.59) \\
{[1.35]} \\
\end{array}$ & $\begin{array}{l}-0.24 \\
(-1.26) \\
{[-0.75]}\end{array}$ & $\begin{array}{l}0.16 \\
(0.85) \\
{[0.49]} \\
\end{array}$ & $\begin{array}{l}-0.13 \\
(-0.72) \\
{[-0.41]}\end{array}$ & $\begin{array}{l}0.42 \\
(2.15)^{* *} \\
{[1.77]^{*}}\end{array}$ & $\begin{array}{l}0.30 \\
(1.82)^{*} \\
{[1.49]}\end{array}$ & $\begin{array}{l}0.19 \\
(2.54)^{* *} \\
{[2.31]^{* *}}\end{array}$ & $\begin{array}{l}0.32 \\
(1.62) \\
{[1.40]} \\
\end{array}$ & $\begin{array}{l}0.43 \\
(1.95)^{*} \\
{[1.67]^{*}}\end{array}$ & 0.41 \\
\hline
\end{tabular}

Note: The table presents Fama-MacBeth (1975) cross-sectional regression results using the excess returns on 25 size- and book-to-market-sorted portfolios. The full sample factor loadings, which are used as the independent variables in the regressions, are computed in one time-series regression. The first row of the table presents the second-stage crosssectional regressions including the intercepts and slopes in percent per month. The Fama-MacBeth (1973) t-statistics are reported in parentheses (FM t-stat) and the t-statistics using errors-in-variables adjustment of Shanken (1992) are reported in square brackets [SH t-stat]. Mktrf is the ex-post excess market return which is equal to the value-weighted CRSP portfolio in excess of the 3-month Treasury bill rate. $G I P_{t}=\ln \left(I P_{t}\right)-\ln \left(I P_{t-1}\right)$, where $I P_{t}$ is the index of industry production in month $t$ from the FRED database at Federal Reserve Bank of St. Louis; $U I_{t}=I_{t}-E\left[I_{t} \mid t-1\right]$ where $I_{t}=\ln \left(C P I S A_{t}\right)-\ln \left(C P I S A_{t-1}\right)$, and $C P I S A_{t}$ is the seasonally adjusted Consumer Price Index from the Labor Bureau of Statistics; $D E I t=E\left[I_{t+1} \mid t\right]-E\left[I_{t} \mid t-1\right]$, where $E\left[I_{t} \mid t-1\right]=R_{f, t}-E\left[R h o_{t} \mid t-1\right], R h o_{t}=R_{f, t}-I_{t}, E\left[R h o_{t} \mid t-1\right]=\left(R_{f, t-1}-I_{t-1}\right)-\left(\hat{v}_{t}+\hat{\varphi} \hat{v}_{t-1}\right)$, and $R_{f, t}$ is the one-month T-bill rate; UTS is defined as a 20-year - 1-year treasury yield from the FRED database at the Federal Reserve Bank of St. Louis; and UPR is defined as the BAA-AAA yield from the FRED database at Federal Reserve Bank of St. Louis. SMB and $H M L$ are Fama and French (1993) size and value factors based on six value-weighted portfolios sorted by size- and book-to-market. The t-statistics marked with ***, **, and * are significant at the $1 \%$, $5 \%$, and $10 \%$ level respectively. 
Table 4: Returns for various sets of portfolios of stocks sorted by the loadings on innovations in the growth rate of industrial production beta and book-to-market (July 1963 - June 2011)

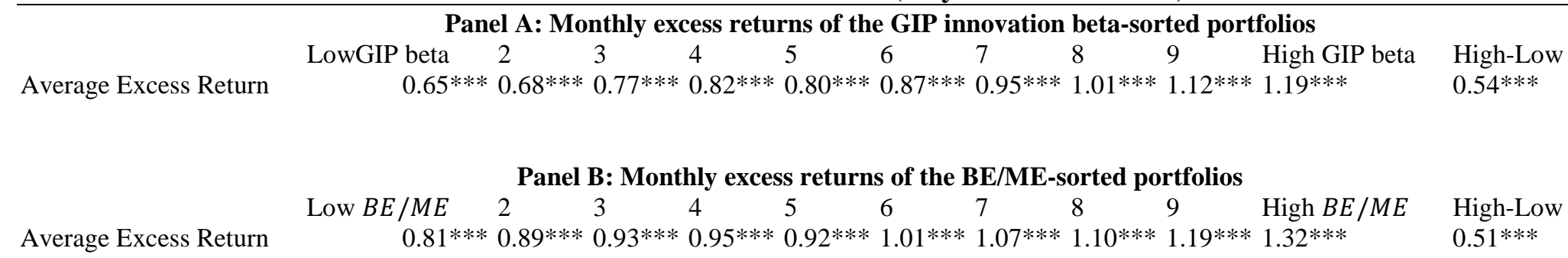

\section{Panel C: Monthly excess returns of the double-sorted portfolios}

Case 1: Stocks are sorted first by BE/ME and then by GIP innovation beta

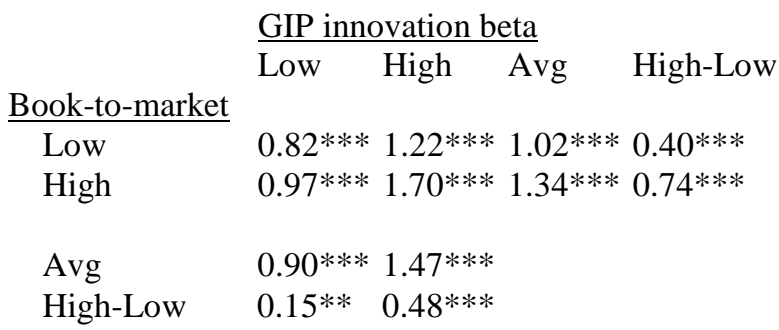

Case 2: Stocks are sorted first by GIP innovation beta and then by BE/ME

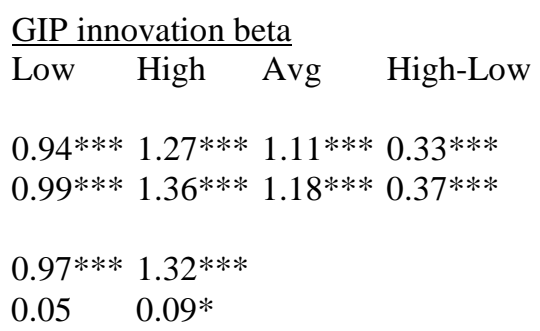

Case 3: Stocks are sorted independently by $\mathrm{BE} / \mathrm{ME}$ and GIP innovation beta

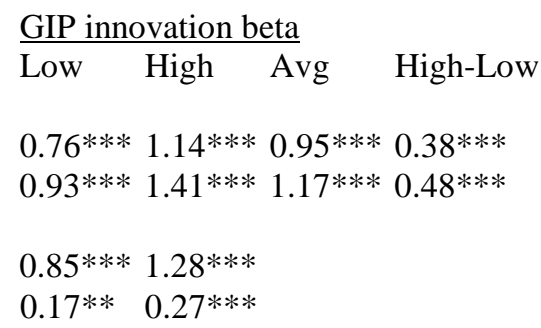

Note: Panel A reports the average monthly excess returns of portfolios of stocks sorted by GIP innovations estimated beta. Panel B reports the average monthly excess returns of portfolios of stocks sorted by $B E / M E$. Panel $C$ reports the average monthly excess returns of portfolios of stocks double-sorted by $B E / M E$ and GIP innovations estimated beta as described in the main text. The $B E$ used in June of year $t$ is the book equity for the last fiscal year end in $t-1$, and the $M E$ is price times shares outstanding at the end of December of $t-1$. The sample includes all ordinary common equity for which we have $M E$ for December of $t-1$ and June of $t$, and $B E$ for $t-1$. For Case 1 , at the end of each June, stocks are sorted into two $B E / M E$ groups (low and high) using the median NYSE breakpoint. The stocks in each group are then sorted into two subgroups (low and high) based on the median value of the GIP innovation beta. The entire double-sorting results in four value-weighted portfolios, the average monthly returns of which are then computed. The portfolios are formed annually and the positions are held over the following 12 months. For Case 2, the order of sorting is reversed: stocks are sorted first into groups by the GIP innovation beta, and then into subgroups by $B E / M E$. For Case 3, we simultaneously sort all the stocks into low and high groups based on the median GIP innovation beta, and into low and high groups based on the median $B E / M E$ breakpoint. *, **, and *** denotes a rejection of zero null hypothesis at the $10 \%$, $5 \%$, and $1 \%$ respectively. 
Table 5: Fama-MacBeth cross-sectional regressions for individual stocks (July 1963 - June 2011)

\begin{tabular}{|c|c|c|c|c|c|c|c|c|c|c|}
\hline Specification & Const & $M k t$ & $\hat{u}^{U I}$ & $\widehat{u}^{D E I}$ & $\hat{u}^{U T S} \quad \hat{u}^{U P R}$ & $\hat{u}^{G I P} \quad \ln (M E)$ & $\ln (B E / M E)$ & $R_{i, t-1}$ & $\sum_{k=2}^{12} R_{i, t-k}$ & $A d j R^{2} \%$ \\
\hline $\begin{array}{l}\text { (1) Estimate } \\
\text { (FM t-stat) }\end{array}$ & $\begin{array}{l}0.080 * * \\
(4.24)\end{array}$ & $\begin{array}{r}* 0.032 \\
(0.77)\end{array}$ & & & & & & & & 1.50 \\
\hline $\begin{array}{l}\text { (2) Estimate } \\
\text { (FM t-stat) }\end{array}$ & $\begin{array}{l}0.042 * * \\
(3.29)\end{array}$ & & & & & $\begin{array}{l}0.041^{* * *} \\
(2.83)\end{array}$ & & & & 2.97 \\
\hline $\begin{array}{l}\text { (3) Estimate } \\
\text { (FM t-stat) }\end{array}$ & $\begin{array}{l}0.093 * * \\
(5.07)\end{array}$ & $\begin{array}{r}* 0.027 \\
(0.51)\end{array}$ & & & & $\begin{array}{l}0.034^{* * *} \\
(2.67)\end{array}$ & & & & 3.03 \\
\hline $\begin{array}{l}\text { (4) Estimate } \\
\text { (FM t-stat) }\end{array}$ & $\begin{array}{l}0.051 * * \\
(3.66)\end{array}$ & $\begin{array}{r}* 0.024 \\
(0.49)\end{array}$ & $\begin{array}{l}0.075 \\
(1.14)\end{array}$ & $\begin{array}{l}-0.057 \\
(-0.91)\end{array}$ & $\begin{array}{l}0.103 * * *-0.041 \\
(2.78) \quad(-1.62)\end{array}$ & $\begin{array}{l}0.045^{* * *} \\
(2.91)\end{array}$ & & & & 5.22 \\
\hline $\begin{array}{l}\text { (5) Estimate } \\
\text { (FM t-stat) }\end{array}$ & $\begin{array}{l}0.040^{* *} \\
(2.95)\end{array}$ & $\begin{array}{r}* 0.015 \\
(0.54)\end{array}$ & & & & $\begin{array}{l}0.037 * * *-0.009 * \\
(2.61) \quad(-1.83)\end{array}$ & $\begin{array}{l}0.021^{* * *} \\
(4.02)\end{array}$ & & & 5.01 \\
\hline $\begin{array}{l}\text { (6) Estimate } \\
\text { (FM t-stat) }\end{array}$ & $\begin{array}{l}0.025 * * \\
(2.41)\end{array}$ & $\begin{array}{l}0.017 \\
(0.63)\end{array}$ & $\begin{array}{l}0.064 \\
(1.09)\end{array}$ & $\begin{array}{l}-0.029 \\
(-0.89)\end{array}$ & $\begin{array}{l}0.097 * *-0.035 \\
(2.34) \quad(-1.55)\end{array}$ & $\begin{array}{ll}0.028 * * & -0.004 \\
(2.53) & (-1.45)\end{array}$ & $\begin{array}{l}0.017^{* * *} \\
(3.79)\end{array}$ & & & 6.13 \\
\hline $\begin{array}{l}\text { (7) Estimate } \\
\text { (FM t-stat) }\end{array}$ & $\begin{array}{l}0.075^{* *} \\
(3.92)\end{array}$ & & & & & $\begin{array}{l}0.39 * * * \\
(2.77)\end{array}$ & & $\begin{array}{l}-0.004 \\
(-1.18)\end{array}$ & & 2.94 \\
\hline $\begin{array}{l}\text { (8) Estimate } \\
\text { (FM t-stat) }\end{array}$ & $\begin{array}{l}0.059^{* *} \\
(3.48)\end{array}$ & & & & & $\begin{array}{l}0.033^{* * *} \\
(2.62)\end{array}$ & & & $\begin{array}{l}0.005^{*} \\
(1.68)\end{array}$ & 3.00 \\
\hline $\begin{array}{l}\text { (9) Estimate } \\
\text { (FM t-stat) }\end{array}$ & $\begin{array}{l}0.021^{* *} \\
(2.35)\end{array}$ & $\begin{array}{l}0.017 \\
(0.66)\end{array}$ & $\begin{array}{l}0.062 \\
(1.02)\end{array}$ & $\begin{array}{l}-0.030 \\
(-0.94)\end{array}$ & $\begin{array}{l}0.091 * *-0.031 \\
(2.20) \quad(-1.46)\end{array}$ & $\begin{array}{ll}0.025^{* *} & -0.005 \\
(2.36) & (-1.52)\end{array}$ & $\begin{array}{l}0.020^{* * *} \\
(3.91)\end{array}$ & $\begin{array}{l}-0.002 \\
(-0.96)\end{array}$ & $\begin{array}{l}0.003 \\
(1.49)\end{array}$ & 6.18 \\
\hline
\end{tabular}




\section{Appendix}

Table A1: Estimation results of the market model and Fama-French three-factor model for 10 GIP innovation beta decile portfolios (January 1962 - December 2011, 600 months)

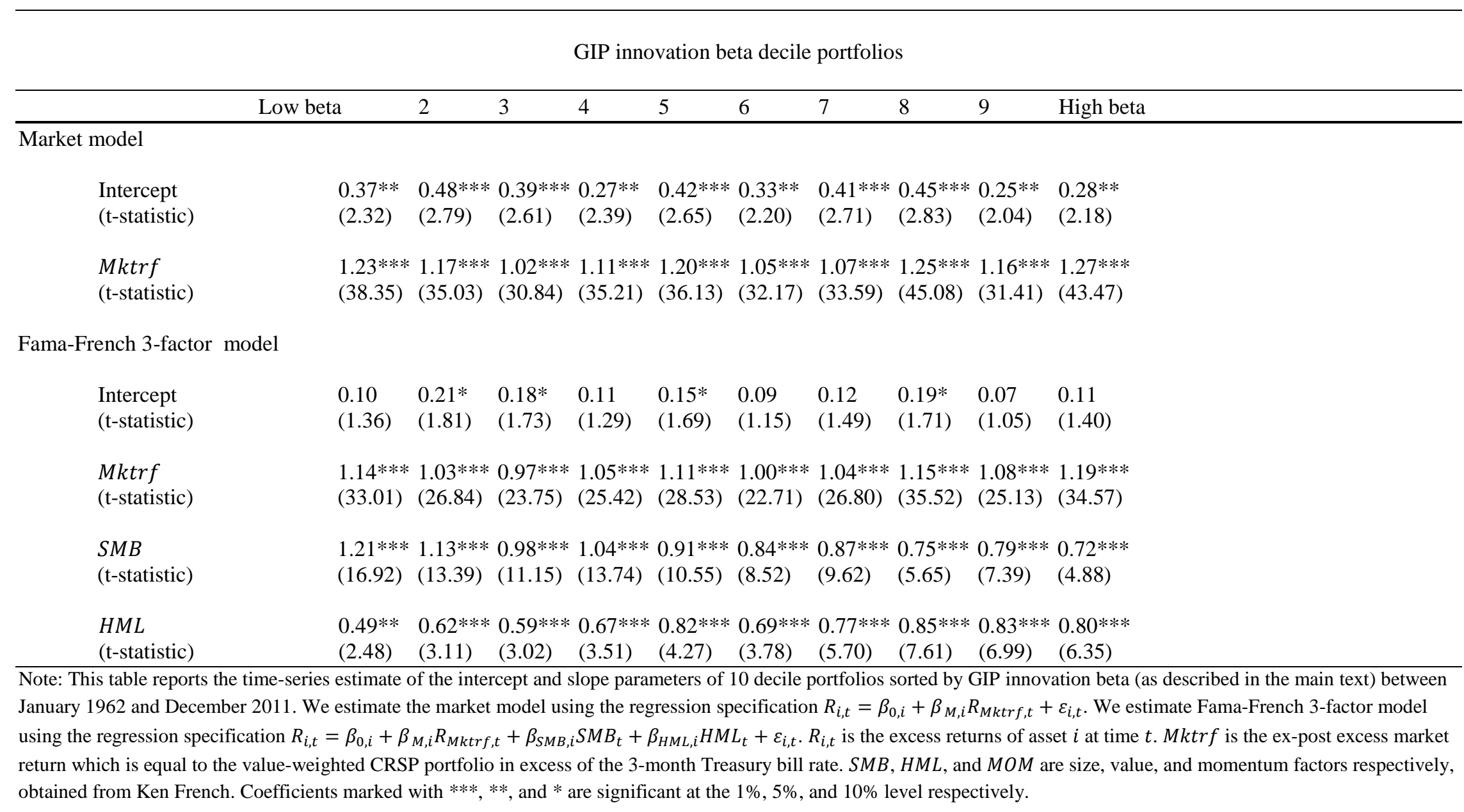

